\title{
ANTIPSYCHOTIC PRESCRIBING PATTERN IN A TERTIARY CARE HOSPITAL OF EASTERN INDIA
}

\author{
*Ghosh Siddhartha ${ }^{1}$, Bhattacharyya Swati ${ }^{2}$, Dalai Chanchal Kumar ${ }^{3}$ \\ ${ }^{1}$ Final year MD PGT (Pharmacology), Department of Pharmacology, Burdwan Medical College \& Hospital, Burdwan, India \\ ${ }^{2}$ Assistant Professor, Department of Pharmacology, Burdwan Medical College \& Hospital, Burdwan, India \\ ${ }^{3}$ Assistant Professor, Department of Pharmacology, College of Medicine \& JNM Hospital, Kalyani, Nadia
}

*Corresponding Author's Email: drsiddharthaghosh83@gmail.com, Phone: 8116033008

\begin{abstract}
:
Background: Psychotropic drugs are commonly prescribed in psychiatric practice., their utilization and consequences on real life effectiveness and safety in actual clinical practice need continuous study.

Materials and Methods: A prospective cross sectional study was carried out for 3 months. All the patients using antipsychotic drugs, between 18-60 years of age, irrespective of sex, were included in the study. However, patients who were pregnant, lactating, unable to comply due to mental retardation, any systemic illness , unconsciousness or drug addiction were excluded from the study. The prescribing pattern was analyzed by Using World Health Organization basic drug indicators.

Results: Average number of drugs /prescription 1.07..atypical antipsychotics are prescribed more commonly than typical antipsychotic.among the atypical antipsychotics olanzapine is most commonly prescribed.monotherapy of antipsychotic is the commonly prescribed than trihexyphenidyl is the anticholinergic that prescribed regularly with typical antipsychotic for the prevension of extrapyramidal symptoms.

Conclusion: Psychotic illness patients mainly advised monotherapy of antipsychotic drugs, mainly atypical antipsychotic drugs, and olanzapine is the most prescribed antipsychotic drugs. Trihexyphenidyl is the only antichoninergic drug coprescribed with typical antipsychotic drugs to avoid extrapyramidal side effects.

Keywords: Drug utilization study, psychotic illness, psychotropic drugs
\end{abstract}

\section{INTRODUCTION}

The World Health Organization (WHO) addressed drug utilization as the marketing, distribution, prescription and use of drugs in a society, considering its consequences, either medical, social, and economic. ${ }^{1}$ Studies on the process of drug utilization focus on the factors related to the prescribing, dispensing, administering, and taking of medication, and its associated events, covering the medical and non-medical determinants of drug utilization, the effects of drug utilization, as well as studies of how drug utilization relates to the effects of drug use, beneficial or adverse. $^{2,3,4}$ The therapeutic practice is expected to be primarily based on evidence provided by pre marketing clinical trials, but complementary data from post marketing period are needed to provide an adequate basis for improving drug therapy. 5

The rapidly expanding field of psychopharmacology is challenging the traditional concepts of psychiatric treatment and research, and is constantly seeking new and improved drugs to treat psychiatric disorders. In this way, psychiatrists are continuously exposed to newly introduced drugs that are claimed to be safe and more efficacious. Although psychotropic medications have had a remarkable impact on psychiatric practice that legitimately can be called revolutionary, their utilization and consequences on real life effectiveness and safety in actual clinical practice need continuous study. ${ }^{6}$

On this background, the study was conducted to evaluate the prescribing pattern of antipsychotic drugs in psychotic illness in a tertiary care teaching hospital in West Bengal.

\section{MATERIALS AND METHODS}

๑) 2011, JDDT. All Rights Reserved

\section{ETHICAL CONSIDERATIONS}

The study protocol, along with the informed consent form (in Bengali, Hindi \& English) was submitted to the Institutional Ethics Committee, Burdwan Medical College, Burdwan, for approval. Subject recruitment commenced only after such approval was obtained in writing.

Informed written consent was taken from the legally acceptable representative of each participant. Illiterate individuals will give their fingerprint (left thumb impression) instead of signature in the presence of an appropriate witness.

\section{STUDY SETTING}

The study was conducted in the Psychiatry out-patient department (OPD) Burdwan Medical College \& Hospital, Kolkata (B.M.C \& H).

Data compilation and Statistical analysis: In Department of Pharmacology, Burdwan Medical College \& Hospital, Kolkata (B.M.C \& H).

STUDY DURATION- The duration of study was three months (October 2012 to January 2013).

\section{STUDY DESIGN:}

The current study was designed as a Cross sectional and unicentric drug utilization study.

\section{SUBJECT SELECTION CRITERIA}

The subjects who had willingly participated were enrolled on the basis of inclusion and exclusion criteria. All the patients using antipsychotic drugs, between 18-60 years of ISSN: 2250-1177
CODEN (USA): JDDTAO 
age, irrespective of sex, were included in the study. However, patients who were pregnant, lactating, unable to comply due to mental retardation, any systemic illness ,unconsciousness or drug addiction were excluded from the study.

\section{STUDY POPULATION:}

The present study was conducted on 510 patients who visited the Psychiatry outdoor unit during October 2012 to January 2013.

\section{PARAMETERS FOR EVALUATION:}

The parameters included gender distribution, age of the patients, type of illness, types of antipsychotic medication prescribed, prescribed in generic form, average number of drugs per prescription, percentage of the drugs prescribed from NLEM 2011(National List of Essential Medicines of India), and percentage of injectable drugs prescribed per day.

\section{STUDY METHODOLOGY:}

This cross-sectional, unicentric study was conducted in the Psychiatry outpatient department (OPD) of an urban, tertiary care, Medical College \& Hospital in west Bengal during October 2012 to January 2013. Prescriptions were collected from patients attending the psychiatry OPD suffering from any psychotic illness. The prescription patterns of antipsychotic agents were analyzed. No follow up of prescription was done.

\section{RESULT AND ANALYSIS}

In a fourth months period from October 2012 to January 2013, a total of 510 patients were included in the study and their prescriptions containing at least one antipsychotic were analyzed only once time- no follow up visit was done. The demographic profile has been described in TABLE 1,2and FIGURE 1, 2 and 3.

Table 1: Shows demographic parameters

\begin{tabular}{|c|c|c|}
\hline PATIENT CHARACTERISTICS & NUMBER OF PRESCRIPTION (N=510) & PERCENTAGE (\%) \\
\hline \multicolumn{3}{|l|}{ AGE IN YEARS } \\
\hline $18-30$ & 265 & 51.9 \\
\hline $31-40$ & 90 & 17.6 \\
\hline $41-50$ & 70 & 13.7 \\
\hline $51-60$ & 60 & 11.7 \\
\hline $61-70$ & 25 & 4.9 \\
\hline \multicolumn{3}{|l|}{ SEX } \\
\hline MALE & 279 & 54.7 \\
\hline FEMALE & 231 & 45.29 \\
\hline \multicolumn{3}{|l|}{ MALE:FEMALE RATIO $1.20: 1$} \\
\hline \multicolumn{3}{|l|}{ DIAGNOSIS } \\
\hline Organic mental disorder (F 0-9) & 15 & 2.94 \\
\hline Mental disorder due to substance abuse (F 10-19) & 25 & 4.9 \\
\hline Schizophrenia delusional disorder (F 20-29) & 235 & 46 \\
\hline Mood disorder (F 30-39) & 155 & 30.39 \\
\hline Neurotic \& somatoform disorder(40-49) & 35 & 6.86 \\
\hline F 50-59 & 0 & 0 \\
\hline $\begin{array}{l}\text { Disorder of adult personality and behavior (F 60- } \\
69 \text { ) }\end{array}$ & 5 & 0.9 \\
\hline Mental disorder (F 70-79) & 20 & 3.9 \\
\hline No diagnosis & 20 & 3.9 \\
\hline \multicolumn{3}{|c|}{$\begin{array}{ll}\text { PRESCRIBING INDICATORS: Average number of drugs /prescription } & 1.07\end{array}$} \\
\hline
\end{tabular}

Table 2: Who recommended prescribing indicators $(\mathrm{N}=\mathbf{5 1 0})$

Average number of antipsychotic drug/prescription

Percentage of the drugs prescribed by generic name

Percentage of the drugs prescribed from NLEM 2011

Percentage of the drugs supplied from hospital pharmacy 


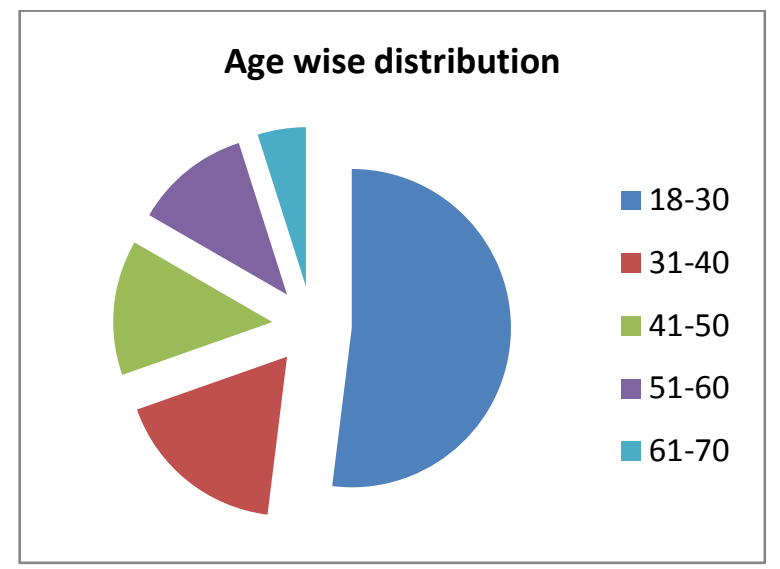

Figure 1: Shows Age-Wise Distribution of Illness

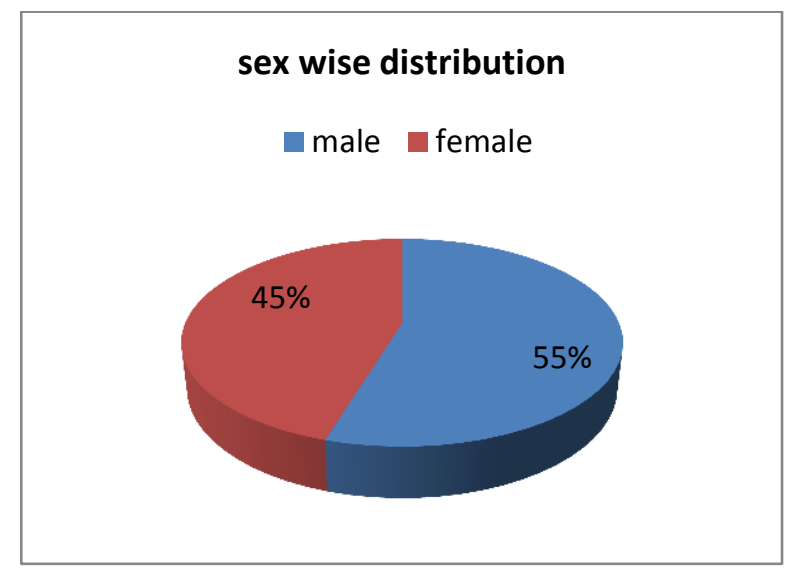

Figure 2: Shows Sex-Wise Distribution Of Illness

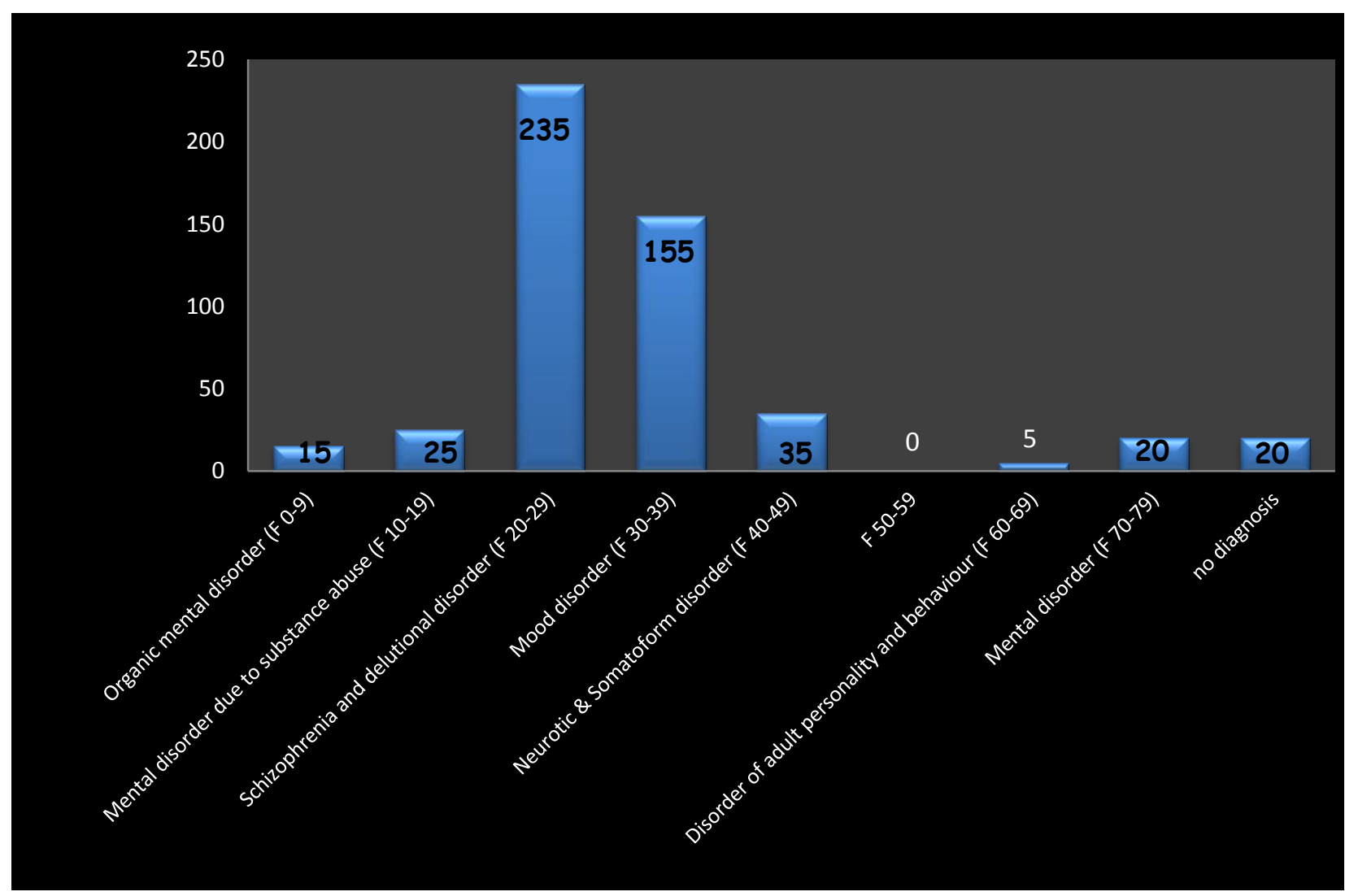

Figure 3: Shows Distribution of Illness

The distribution of drugs according to drug category-either atypical or typical antipsychotic are tabulated in table no 3.

Table 3: Distribution of drugs (total no of prescribed drugs $\mathrm{N}=545$ )

\begin{tabular}{|l|l|c|c|}
\hline \multicolumn{1}{|c|}{ Type of drug } & \multicolumn{1}{|c|}{ Name } & No & Percentage \\
\hline \multirow{3}{*}{ Atypical antipsychotic } & Olanzapine & 420 & 77.06 \\
\cline { 2 - 4 } & Risperidone & 45 & 8.26 \\
\cline { 2 - 4 } & Quetiapine & 10 & 1.83 \\
\hline \multirow{2}{*}{ Typical antipsychotic } & Haloperidol & 60 & 11 \\
\cline { 2 - 4 } & Trifluperidol & 10 & 1.83 \\
\hline Anticholinergic & Trihexyphenidyl & 60 & 11 \\
\hline
\end{tabular}

From the previous table it is seen that olanzapine were prescribed in higher number. The doses (mg/day) of olanzapine in various psychotic illness are tabulated in table no 4. 


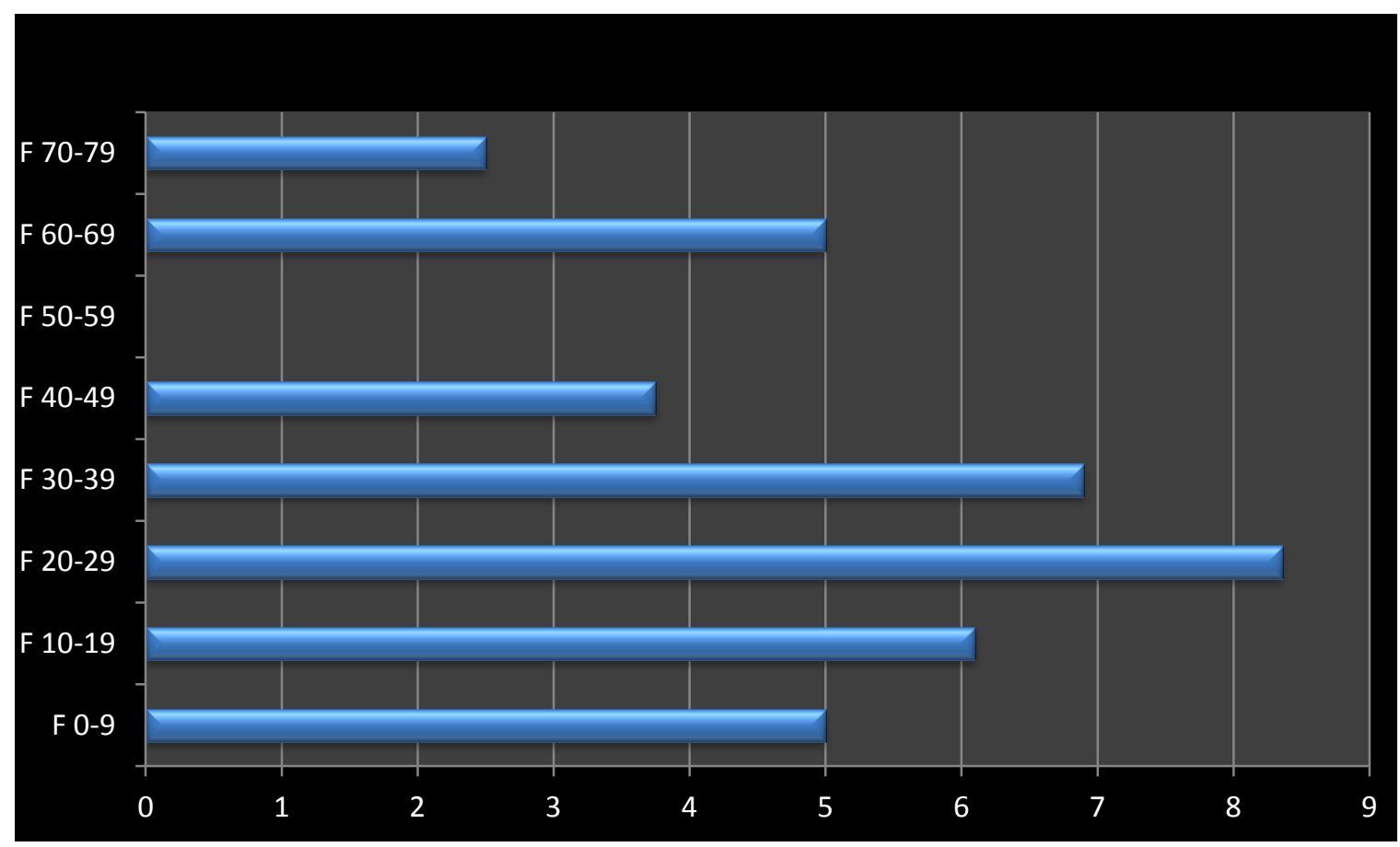

Figure 4: Doses ((Mg/Day) of Olanzapine in Various Psychotic Illnesses

The antipsychotic drugs were either prescribed in combination or singly in each prescription. But it was seen that majority prescription contained single antipsychotic drug, presented in table no 3 (total prescription =510) and figure no 4.

\section{Table 4: Distribution of Prescription (Total No of} Prescription, $\mathrm{N}=510$ )

\begin{tabular}{|lc|c|c|}
\hline Type of prescription & $\begin{array}{c}\text { Number of } \\
\text { prescription }\end{array}$ & $\begin{array}{c}\text { Percentage } \\
\text { (\%) }\end{array}$ \\
\hline $\begin{array}{l}\text { Monotherapy of } \\
\text { antipsychotic }\end{array}$ & 480 & $94 \%$ \\
\hline $\begin{array}{l}\text { Polytherapy of } \\
\text { antipsychotic }\end{array}$ & 30 & $6 \%$ \\
\hline
\end{tabular}

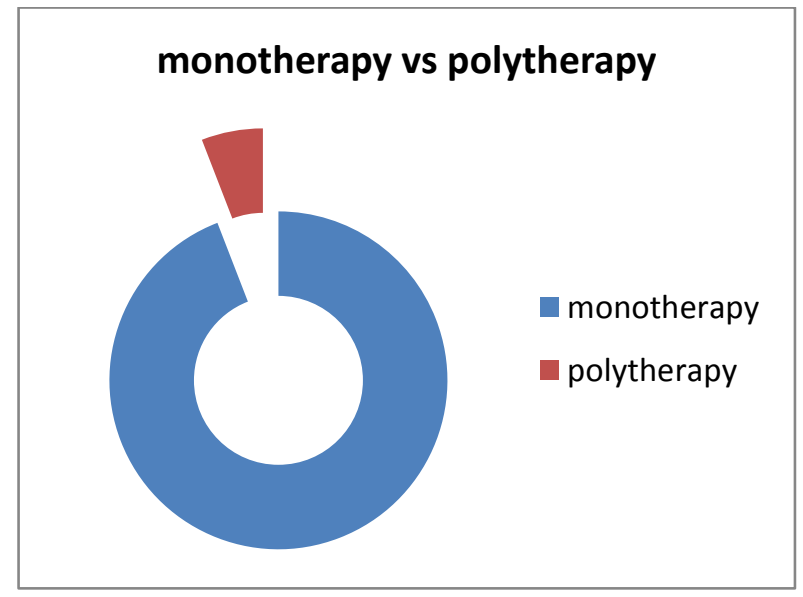

Figure 5: Shows Prescription Pattern either MonoTherapy or Poly-Therapy

During analysis of prescription it was seen that maximum drugs were supplied from the hospital in free of cost where less percentage of drugs were purchases from outsides, represented in figure 6 .

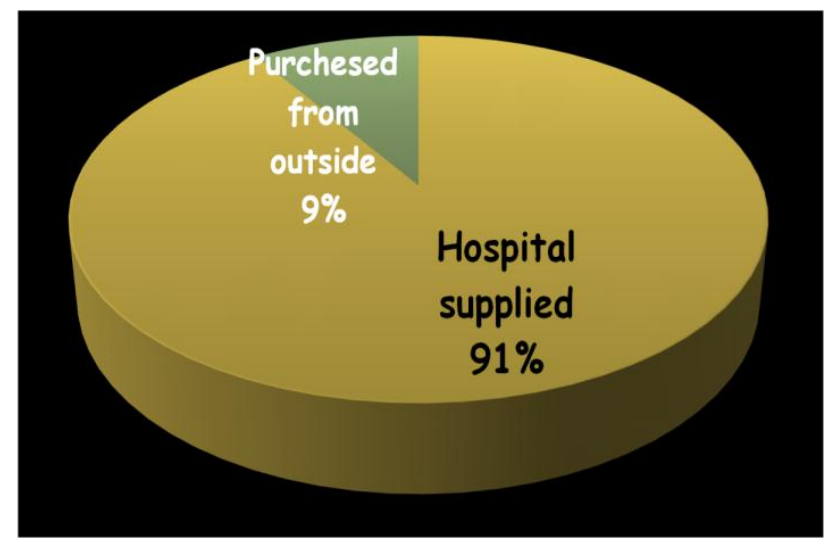

Figure 6: Sources of Drugs

\section{DISCUSSION}

Most of the published guidelines for the use of antipsychotic favor the use of atypical ones, ${ }^{7}$ the majority of the patients $(87.15 \%)$ [475/545] in this study, were receiving the atypical antipsychotic medications particularly olanzapine and risperidone. Less than $13 \%$ [70/545] patients received the typical antipsychotics. This is in accordance with the general findings that clinical efficacy and safety of these conventional antipsychotics were shown to be less than that of atypical new generation antipsychotic medications. ${ }^{8,9}$

Schizophrenia was more common in males. Disorder was more common in the age group of 18-30 years.

In the governmental sector, the majority of patients in west Bengal who are receiving typical antipsychotic medications are usually denied access to the newer atypical drugs until they have failed to respond to or tolerate conventional treatments. This pattern of usage is not due to unavailability atypical antipsychotic, rather, it might be due to the cost difference between the typical and atypical antipsychotic. 
Among those patients receiving the typical antipsychotic medications, (22/124) were receiving two - drug combination antipsychotics. Similar patterns of polypharmacy have been noted in other countries.

In Australia, one study shows 13 percent of all outpatients received more than one antipsychotic medication, ${ }^{10}$ in another study, 47 percent of patients received prescriptions for two antipsychotic medications, and 8 percent received prescriptions for three medications. ${ }^{11}$

In our study group, approximately $6 \%$ of the patients were receiving multiple antipsychotic medications.

Important findings were drug prescribed in generic form in higher percentage $(92.66 \%)$ and majority of drugs $(89.89 \%)$ prescribed from NLEM 2011.The reason may be due to free supply of medicine in government hospital.

Finally, it was seen that, prescription containing typical antipsychotic drugs also contained anticholinergic agent

\section{REFERENCES}

1. WHO Expert Committee. The Selection of Essential Drugs, technical Report Series no.615. Geneva: World Health Organization, 1977.

2. Lunde PK, Baksaas I. Epidemiology of drug utilization basic concepts and methodology, Acta Med Scand Suppl. 1988; 721:7-11.

3. Strom BL. Pharmacoepidemiology. Fourth ed: John Wiley\& Sons, Ltd. 2005.

4. Costa J, Rosa MM, Ferreira JJ, Sampaio C, Vaz Carneiro A. [Cardiac effects of acute poisoning with tricyclic antidepressants: systematic review of the literature. Part I], Rev Port Cardiol. 2001; 20:671-8.

5. Strom BL, Melmon KL, Miettinen OS. Postmarketing studies of drug efficacy, Arch Intern Med. 1985; 145:1791-4.

6. Piparva K. G.,Parmar D. M.,Singh A. P.,Gajera M. V.,Trivedi H. R.Drug Utilization Study of Psychotropic Drugs in Outdoor due to protective effect against extrapyramidal side effects of the neuroleptic drugs. Trihexyphenidyl was the only anticholinergic drug prescribed by psychiatrists in Burdwan Medical College \& Hospital. This underutilization of the protective anticholinergic medications to be co-prescribed with typical antipychotics increases the risk of extrapyramidal side effects and other toxicities.

\section{CONCLUSION}

To conclude, our study shows, patients suffering from psychotic illness mainly advised monotherapy of antipsychotic drugs, mainly atypical antipsychotic drugs, and olanzapine is the most prescribed antipsychotic drugs.

Trihexyphenidyl is the only antichoninergic drug coprescribed with typical antipsychotic drugs to avoid extrapyramidal side effects.

Patients in a Teaching Hospital.Indian J Psychol Med. 2011; 33(1): $54-58$

7. Csernansky, J.G., A comparison of risperidone and haloperidol for the prevention of relapse in patients with schizophrenia, $\mathrm{N}$ Engl J M. 2002; 346(1): 16-22.

8. Serretti A, De Ronchi D, Lorenzi C, Berardi D. New antipsychotics and schizophrenia: a review on efficacy and side effects. Curr Med Chem. 2004; 11(3):343-58.

9. Freedman R.Schizophrenia.N Engl J Med. 2003; 349(18):173849.

10. Keks, N.A. et al. Use of antipsychosis and adjunctive medications by an inner urban community psychiatric service. Australian and New Zealand Journal of Psychiatry. 1999; 33: 896-901.

11. Rittmannsberger, H. et al. Polypharmacy in psychiatric treatment: patterns of psychotropic drug use in Austrian psychiatric clinics. European Psychiatry. 1999; 14: 33-40. 